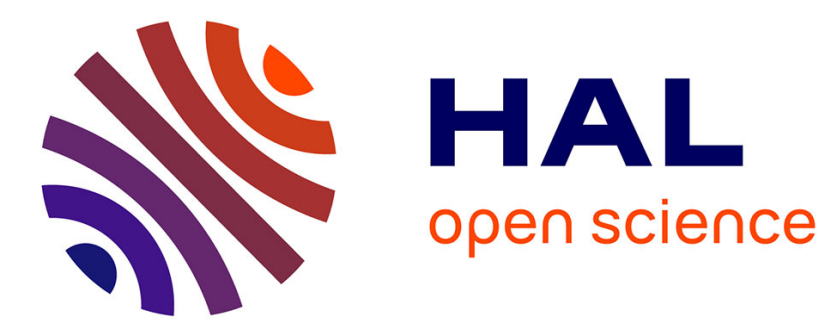

\title{
Isothermal and cyclic oxidation of TiAl composites
}

J. Fish, D. Duquette

\section{To cite this version:}

J. Fish, D. Duquette. Isothermal and cyclic oxidation of TiAl composites. Journal de Physique IV Proceedings, 1993, 03 (C9), pp.C9-411-C9-418. 10.1051/jp4:1993943 . jpa-00252383

\section{HAL Id: jpa-00252383 https://hal.science/jpa-00252383}

Submitted on 1 Jan 1993

HAL is a multi-disciplinary open access archive for the deposit and dissemination of scientific research documents, whether they are published or not. The documents may come from teaching and research institutions in France or abroad, or from public or private research centers.
L'archive ouverte pluridisciplinaire HAL, est destinée au dépôt et à la diffusion de documents scientifiques de niveau recherche, publiés ou non, émanant des établissements d'enseignement et de recherche français ou étrangers, des laboratoires publics ou privés. 


\title{
Isothermal and cyclic oxidation of TiAl composites
}

\author{
J.S. Fish and D.J. Duquette
}

Rensselaer Polytechnic Institute, Materials Engineering Department, Troy, 12180-3590, N.Y., U.S.A.

\begin{abstract}
Titanium Aluminide and TiAl matrix composites reinforced with alumina fibers (PRD166) were fabricated by powder metallurgy. During isothermal oxidation at 950 and $1070{ }^{\circ} \mathrm{C}$, composites containing PRD166 fibers exhibited larger weight gains than monolithic TiAl; the composites showed evidence of oxidation along the perimeter of the fibers. A fiber reaction, which was observed after oxidation in air, is believed to result from internal oxidation. The reaction was suppressed by heat treating in vacuum and increasing the aluminum content of the matrix. The oxide adherence on TiAl was improved by the addition of alumina (PRD166) fibers.
\end{abstract}

\section{Introduction.}

Titanium aluminides are being considered for high temperature structural applications, such as the National Aerospace Plane and rotors in automobile superchargers. However, similar to other intermetallics, TiAl suffers from a lack of room temperature ductility, inadequate creep resistance, and susceptibility to hydrogen embrittlement. Fiber reinforcement is being studied as a means to improve the damage tolerance, creep resistance, and specific strength of titanium aluminides.

The maximum operating temperature of titanium aluminides will be limited by oxidation resistance rather than by creep or strength retention [1]. Therefore, an understanding of the oxidation mechanisms of these materials is essential. Oxidation of binary Ti-Al alloys produces mixed oxides of $\mathrm{Al}_{2} \mathrm{O}_{3}$ and $\mathrm{TiO}_{2}$. During oxidation at $1100{ }^{\circ} \mathrm{C}$ in air, a continuous alumina film is formed only on $\mathrm{Ti}-\mathrm{Al}$ alloys containing more than $42-45 \%$ ( ${ }^{1}$ ) aluminum [2].

While several studies of the mechanical properties of titanium aluminide composites have been conducted, very little research has been published on the oxidation behavior of these composites. The purpose of this study was to examine the oxidation behavior of TiAl composites containing alumina reinforcements.

\section{Experimental procedures.}

The material used in this study was fabricated by powder metallurgy using elemental titanium and aluminum powders. Dupont's advanced alumina fiber, PRD166, was chosen as the reinforcement for the composites. The composition and size of the powders and fibers are shown in table I. The Dupont PRD166 fiber contains $15 \%$ stabilized zirconia to improve the fiber's creep resistance and ultimate tensile strength [3]. The composition of the monolithic TiAl and the matrix of the composites was $40 \%$ (54 at.\%) aluminum, which corresponds to single phase gamma on the Ti-Al phase diagram.

( ${ }^{1}$ ) Compositions in wt.\% 
Table I. - Powders and PRD166 fibers.

\begin{tabular}{|c|c|c|c|}
\hline Powders & Diameter $(\mu \mathrm{m})$ & Composition & Source \\
\hline Aluminum & 8 & $99^{+} \% \mathrm{Al}$ & Valimet \\
Titanium & 36 & $99^{+} \% \mathrm{Ti}$ & Micron Metals \\
PRD166 & 20 & $85 \% \mathrm{Al}_{2} \mathrm{O}_{3}, 15 \% \mathrm{ZrO}_{2}$ & Dupont \\
\hline
\end{tabular}

The PRD166 fibers were chopped to lengths of $3 \mathrm{~mm}$ and mixed with ethanol to reduce agglomeration. The chopped fibers were then mixed with the elemental titanium and aluminum powders, cold isostatically pressed at $242 \mathrm{MPa}$ ( $35 \mathrm{ksi}$ ), pre-reacted at $800^{\circ} \mathrm{C}$ for 45 minutes, and then consolidated by hot isostatic pressing at $1350^{\circ} \mathrm{C}$ and $173 \mathrm{MPa}(25 \mathrm{ksi}$ ) for two hours.

Oxidation samples were polished to $0.3 \mu \mathrm{m}$ alumina and ultrasonically cleaned with acetone and ethanol. Isothermal oxidation experiments were performed using alumina boats in dry air over the temperature range of 950 to $1070^{\circ} \mathrm{C}$. Cyclic oxidation experiments, to evaluate oxide adherence, consisted of ten hour cycles at temperature followed by cooling in static air. Weight change measurements were used to determine the oxidation resistance of the composites. Oxide morphology, adherence, and composition were evaluated by X-ray diffraction, scanning electron microscopy (SEM), energy dispersive analysis by X-ray (EDAX), and electron microprobe analysis (EMPA).

\section{Results and discussion.}

3.1 TiAl-PRD166 OxIDATION. - Oxidation weight change measurements of the PRD166 reinforced composites are shown in figures 1 and 2. The specific weight gain of the composites was greater than that of monolithic TiAl and increased proportionally with the volume fraction of reinforcement.

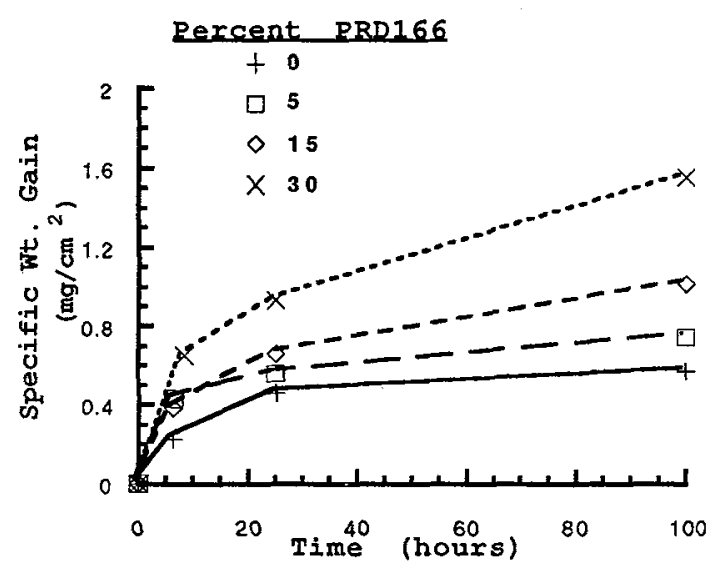

Fig. 1. - Specific weight gain during isothermal oxidation at $950^{\circ} \mathrm{C}$ in air. 


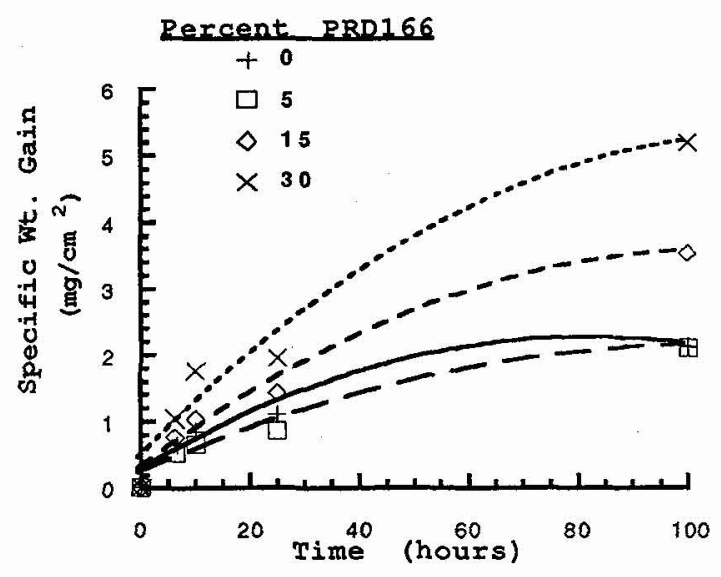

Fig. 2. - Specific weight gain during isothermal oxidation at $1070{ }^{\circ} \mathrm{C}$ in air.

Figures 3 and 4 show SEM micrographs of the oxide morphology and cross sections of the oxide after oxidation for 100 hours at $1070^{\circ} \mathrm{C}$. Approximately $40 \%$ of the monolithic sample was covered with a convoluted oxide and the rest of the surface contained a highly faceted oxide. These oxides were identified by X-Ray diffraction and $\mathrm{EDAX}$ as $\mathrm{Al}_{2} \mathrm{O}_{3}$ and $\mathrm{TiO}_{2}$, respectively. Figure 3 shows that the matrix of the composites was convered by a buckled $\mathrm{Al}_{2} \mathrm{O}_{3}$ film and that an external oxide was not formed on the surface of the PRD166 fibers.

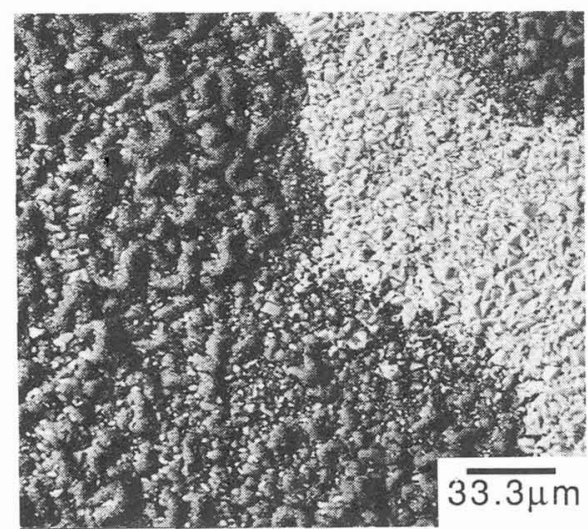

a)

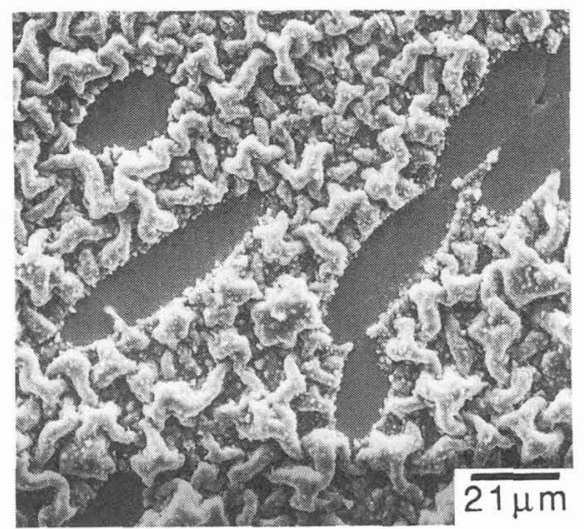

b)

Fig. 3. - SEM micrographs ( $\mathrm{a}$ is a backscattered electron image and $\mathrm{b}$ is a secondary electron image) of external oxide morphology after 100 hours at $1070^{\circ} \mathrm{C}$. (a-TiAl, b- TiAl- 15\% PRD166).

Based on SEM observations of oxidized samples, a schematic model of the oxidation of TiAl $(40 \% \mathrm{Al})$ at $1070^{\circ} \mathrm{C}$ is presented in figure 5 . During the initial stages of oxidation, both rutile and alumina nucleate on the sample surface. Oxidation exposures for less than one hour indicate that a buckled alumina layer initially forms. Golightly et al. [4] proposed that 


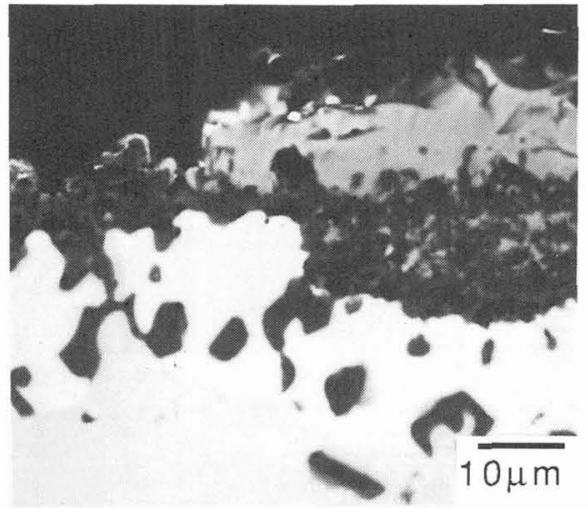

a)

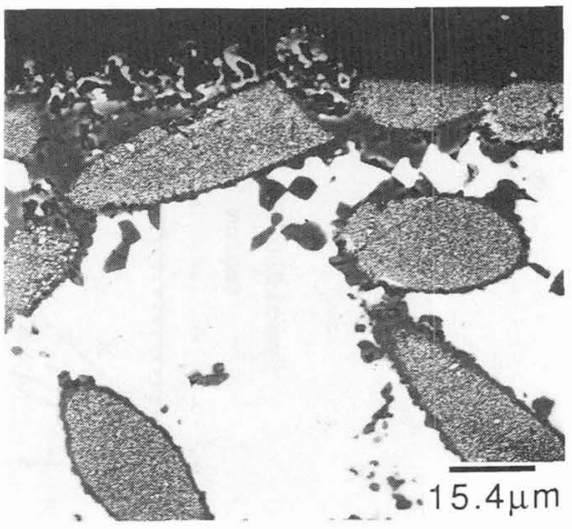

b)

Fig. 4. - Backscattered electron micrographs of oxide cross-sections after 100 hours at $1070{ }^{\circ} \mathrm{C}$. (a-TiAl, b- TiAl- 15\% PRDI66).

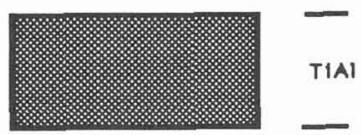

(a)

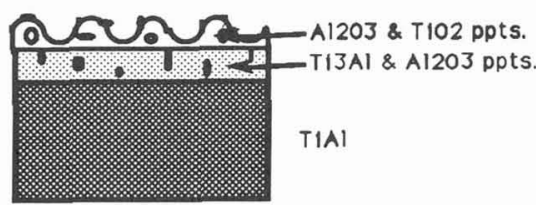

(c)

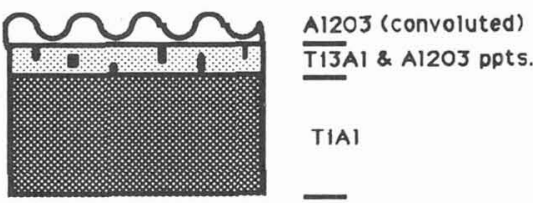

(b)

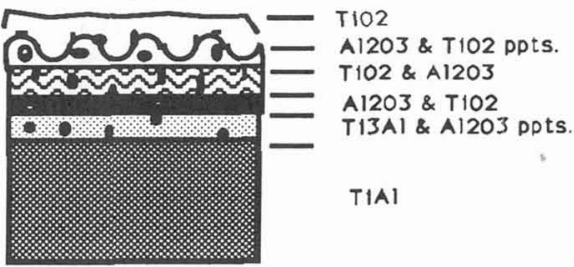

(d)

Fig. 5. - Schematic model for the oxidation of $\mathrm{TiAl}$ at $1070^{\circ} \mathrm{C}$ : a) initial TiAl surface; b) formation of $\mathrm{Al}_{2} \mathrm{O}_{3}$ film; c) heterogeneous oxide and internal oxidation; and d) external $\mathrm{TiO}_{2}$ formation.

compressive stresses, resulting from oxide nucleation and growth within the parent $\mathrm{Al}_{2} \mathrm{O}_{3}$ film, are responsible for the buckled oxide.

Formation of the alumina film depletes the substrate of aluminum and produces the $\operatorname{Ti}_{3} \mathrm{Al}$ zone shown in figure $4 \mathrm{a}$. The lower aluminum content of the $\mathrm{Ti}_{3} \mathrm{Al}$ promotes internal oxidation, producing $\mathrm{Al}_{2} \mathrm{O}_{3}$ precipitates and further reducing the aluminum content. As the activity of titanium increases (and the activity of aluminum decreases), titanium oxide formation becomes more favorable than alumina formation. Continued oxidation produces a heterogeneous oxide consisting of alternating layers of rutile and alumina, shown in figures $5 \mathrm{c}$ and $5 \mathrm{~d}$.

Depending on the aluminum content, the alumina film shown in figure $5 \mathrm{~b}$ may be dis- 


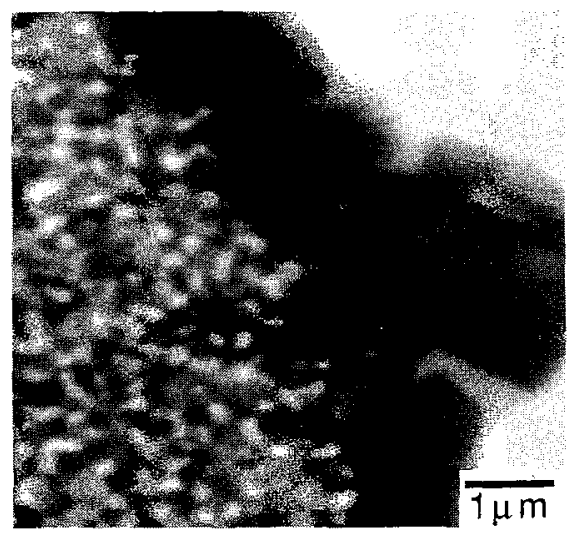

a)

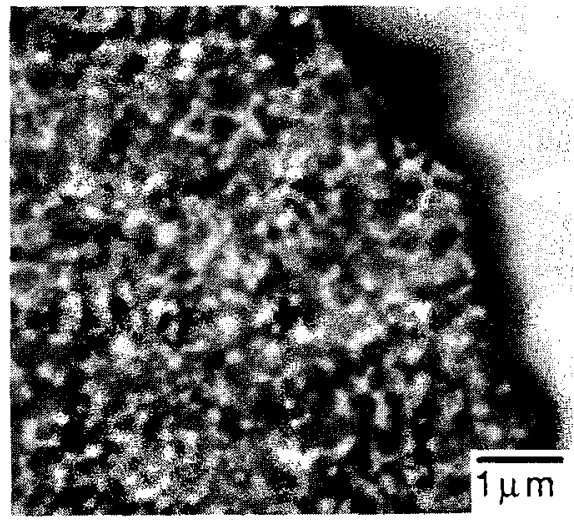

b)

Fig. 6. - Back scattered electron micrograph of a alumina layer on the perimeter of the PRD166 fibers after oxidation for 100 hours at $1070^{\circ} \mathrm{C}$ : a) location near the surface of the composite; b) location at the center of the composite.

continuous; Meier et al. [2] showed that approximately $42-45 \%$ aluminum is necessary for continuous alumina film formation on binary TiAl during oxidation in air at $1100^{\circ} \mathrm{C}$. Ti-Al alloys without sufficient aluminum content to produce a continuous $\mathrm{Al}_{2} \mathrm{O}_{3}$ film form a thick external oxide of $\mathrm{TiO}_{2}[5,6]$. Figures $4 \mathrm{a}$ and 5 d show a $\mathrm{TiO}_{2}$ oxide which formed over a discontinuous alumina scale. The rutile layer may result from the outward diffusion of titanium through gaps in the $\mathrm{Al}_{2} \mathrm{O}_{3}$ film or may result from other rapid diffusion paths. Voids, which have been reported at oxide-metal interface [6], may be Kirkendall porosity resulting from outward titanium diffusion and are expected to reduce the integrity of the oxide-metal bond.

In contrast to monolithic TiAl, the PRD 166 composites did not develop a stratified oxide or a thick external $\mathrm{TiO}_{2}$ layer. In addition, figure $4 \mathrm{~b}$ shows evidence of oxidation along the perimeter of the fibers. The alumina layer along the fibers was thickest near the surface of the composite and diminished towards the center, as shown in figure 6. Oxygen diffusion along the fibers and subsequent oxidation of the matrix along the perimeter of the fibers is believed to be responsible for the increased weight gain of the composites; Tortorelli $\mathrm{et} \mathrm{al}$. [7] reported that $\mathrm{Ni}_{3} \mathrm{Al}$ reinforced with PRD166 and FP fibers exhibited larger weight gains than unreinforced $\mathrm{Ni}_{3} \mathrm{Al}$.

3.2 PRD166 REACTION. - A fiber-matrix reaction, shown in figure 7, occurred at some of the fibers, predominantly at fiber clusters, during oxidation at 950,1020 and $1070{ }^{\circ} \mathrm{C}$ in air. Measurements of the reaction zone indicate that it grows at a parabolic rate. EMPA revealed that the dark precipitates are $\mathrm{Al}_{2} \mathrm{O}_{3}$; in addition, the matrix adjacent to the reaction zone was doped with about $2.5 \%$ zirconium.

Nourbakhsh et al. [8] found that TiAl (Mn)-PRD166 composites produced by pressure casting were doped with zirconium and formed zirconia at the fiber-matrix interface. This effect was attributed to creep of the fiber which swept zirconia to the fiber perimeter and into the matrix. However, Nourbakhsh's study did not include any oxidation experiments or report anything similar to the reaction in figure 7 .

The matrix-PRD166 reaction does not result from an inherent fiber-matrix incompatibility. Diffusion couple experiments have shown that $\mathrm{Al}_{2} \mathrm{O}_{3}$ is stable with gamma TiAl [9]. Above 


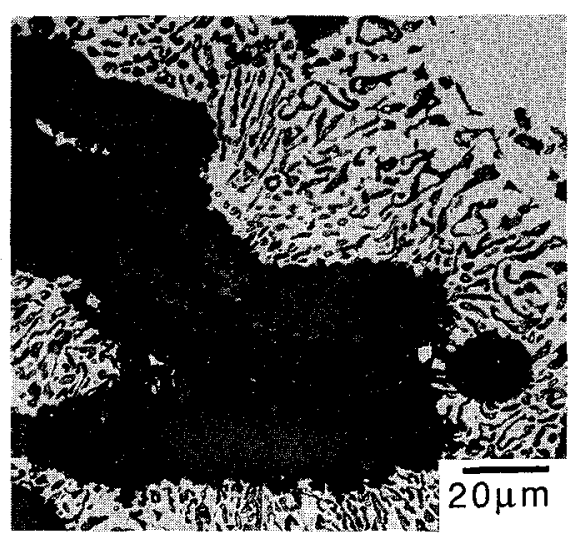

a)

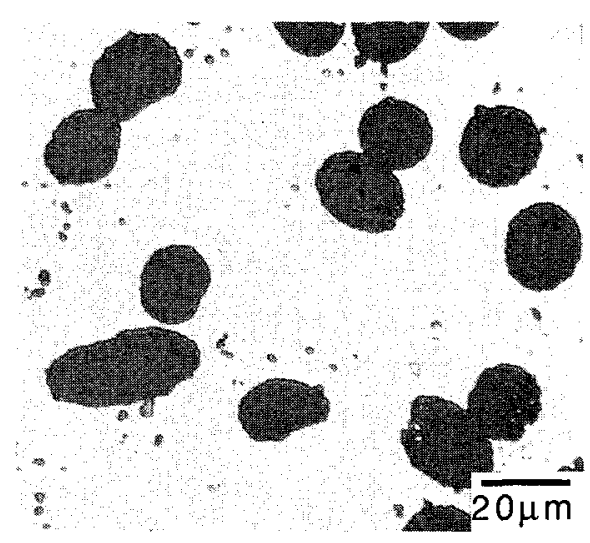

b)

Fig. 7. - Microstructure of TiAl-30\% PRD166 after $100 \mathrm{~h}$ at $1070^{\circ} \mathrm{C}$ : a) air; b) vacuum encapsulated in quartz; $\approx 10^{-7}$ torr.

$1000^{\circ} \mathrm{C}$, zirconia is thermodynamically more stable than alumina [10]. A sample containing $30 \%$ PRD166 was heat treated for 100 hours at $1070{ }^{\circ} \mathrm{C}$ in an evacuated quartz tube, and figure $7 \mathrm{~b}$ shows that the reaction did not occur after this heat treatment. Therefore, the reaction is most likely related to oxygen diffusion and reaction with the matrix along the PRD166 fibers.

Wagner [11] derived an expression for the critical aluminum content, $N_{\mathrm{Al}}^{*}$, necessary to prevent internal oxidation. The critical aluminum content is dependent on the volume fraction of internal precipitates, $g$, and the ratio of the diffusivity of oxygen and aluminum in the matrix, $D_{\mathrm{o}} / D_{\mathrm{Al}}$. Other variables in equation (1) include the oxygen solubility in the alloy, $N_{\mathrm{o}}$, and the molar volumes of the oxide, $V_{\mathrm{ox}}$, and of the alloy, $V_{\mathrm{m}}$. Internal oxidation occurs when the oxygen flux into the alloy is greater than the counter flux of aluminum. At a critical volume fraction of internal precipitates, $g^{*}$, the oxygen flux is reduced by the alumina precipitates to allow the formation of a continuous alumina film.

$$
N_{\mathrm{Al}}^{*}=\sqrt{\frac{\pi g^{*} N_{\mathrm{o}} D_{\mathrm{o}} V_{\mathrm{m}}}{3 D_{\mathrm{Al}} V_{\mathrm{ox}}}}
$$

The following model is presented to explain the matrix-PRD166 reaction and the accelerated weight gain of the composites. As a result of stress assisted diffusion at the high fabrication temperature $\left(1350^{\circ} \mathrm{C}\right)$ and pressure $(173 \mathrm{MPa})$, the TiAl matrix is doped with zirconium and a zirconia sheath forms at the perimeter of the fibers. For example, TEM results by Nourbakhsh [12] have shown that $\mathrm{ZrO}_{2}$ is present at the fiber-matrix interface of intermetallic composites produced by pressure casting. Figure 3 shows that the fiber ends are not covered by an oxide film, thus allowing a constant supply of oxygen to the reaction zone surrounding the fibers. The diffusivity of oxygen in zirconia at $1070{ }^{\circ} \mathrm{C}$ is approximately eleven orders of magnitude faster than in alumina $[13,14]$. A previous study has shown that zirconium increases the oxygen diffusivity in titanium [15]. If $\mathrm{Zr}$ has the same effect in TiAl, equation (1) indicates that a greater aluminum content will be required to prevent internal oxidation along the fibers. 
By increasing the aluminum content of the matrix, it should be possible to prevent the internal oxidation adjacent to the fibers. Two PRD166 composites were fabricated with $44 \%$ and $48 \%$ aluminum and oxidized in air for 100 hours at $1070^{\circ} \mathrm{C}$. The reaction was observed in the sample containing $44 \%$ aluminum but not in the TiAl-PRD 166 composite containing $48 \%$ aluminum.

3.3 GYCLIC OXIDATION. - The results of cyclic oxidation experiments performed at $1070^{\circ} \mathrm{C}$ are presented in figure 8 . The oxide adherence on monolithic TiAl is poor, as indicated by the spalling and subsequent rapid weight gain. In contrast, none of the composites exhibited any spalling.

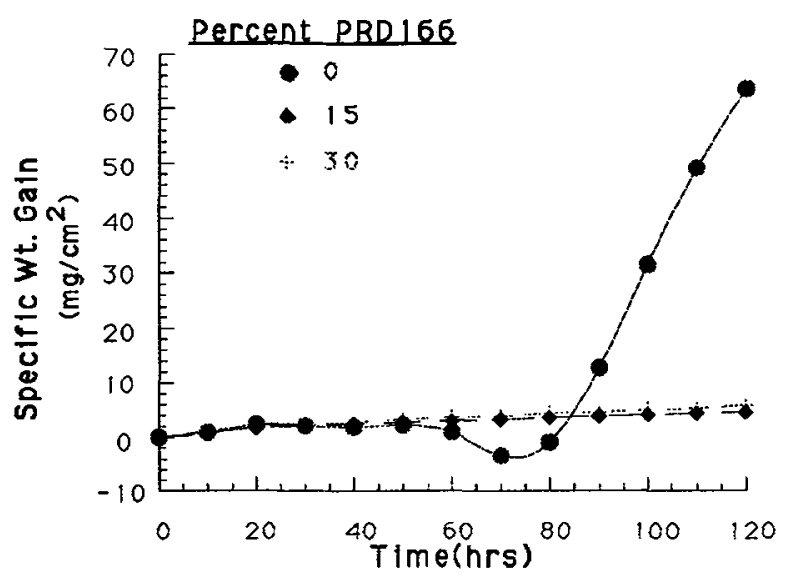

Fig. 8. - Specific weight gain during cyclic oxidation at $1070^{\circ} \mathrm{C} .(1 \mathrm{cycle}=10$ hours $)$.

Oxide adherence on $\mathrm{Ti}-\mathrm{Al}$ alloys appears to be associated with the ability to form a continuous alumina film and the absence of a thick external $\mathrm{TiO}_{2}$ scale. The monolithic $\mathrm{TiAl}$ formed a rutile layer which spalled and cracked during thermal cycling. However, the oxide on the composites, which was similar to that produced during isothermal oxidation, was adherent up to 120 hours.

Examination of spalled films indicates that oxide failure typically occurs at the oxide-metal interface. A possible explanation is that this interface has been weakened by Kirkendall voids, resulting from the outward diffusion of titanium. In any case, precluding the formation of $\mathrm{TiO}_{2}$ appears to improve oxide adherence. Perkins [16] showed that a continuous alumina layer, promoted by chromium and vanadium additions, prevented the formation of an external $\mathrm{TiO}_{2}$ scale and improved the oxide adherence of the alloy. The cyclic oxidation resistance of TiAl was significantly improved by promoting alumina formation with a low oxygen pressure pre-treatment [17].

According to Wagner's internal oxidation theory, the formation of a continuous film will occur at a critical volume fraction of internal precipitates, $g^{*}$. If the alumina reinforcements act as internal precipitates, then it may be possible to form a continuous $\mathrm{Al}_{2} \mathrm{O}_{3}$ film at a lower aluminum content than without the reinforcements. Thus, alumina fibers may inhibit outward titanium diffusion by promoting a continuous scale of $\mathrm{Al}_{2} \mathrm{O}_{3}$ and, thereby, improve the cyclic oxidation resistance of TiAl composites. 


\section{Summary.}

TiAl reinforced with PRD 166 fibers exhibited increased weight gain during oxidation in air, as compared to monolithic TiAl. Oxygen diffusion along the alumina reinforcement formed an $\mathrm{Al}_{2} \mathrm{O}_{3}$ layer along the perimeter of the fibers. It is postulated that zirconium from the PRD166 fibers increases the oxygen diffusivity in the matrix and promotes internal oxidation adjacent to the fibers; this reaction may be suppressed by heat treating in vacuum or increasing the aluminum of the matrix.

The addition of PRD 166 fibers significantly improves the oxide adherence during cyclic oxidation. One possible explanation is that the fibers promote the formation of a continuous $\mathrm{Al}_{2} \mathrm{O}_{3}$ film. Further experiments are planned to determine if zirconium is necessary for the improved adherence.

\section{Acknowledgements.}

Research supported by DARPA-ONR Contract No. NOOO14-86-K0770.

\section{References}

[1] KIM Y.W., JOM (July 1989) p. 24.

[2] MeIER G.H. et al., Oxidation of High Temperature Intermetallics, T. Grobstein, J. Doychak Eds. (TMS PA, 1989) p. 185.

[3] LEWIS G.K., ROMINE J.C., 32nd SAMPE Symposium (1987).

[4] Golightly F.A. et al., J. Electrochem. Soc. 126 (1979) 1035.

[5] Choudhury N.S. et al., Proc. of Symposium on Properties of High Temperature Alloys, Z.A. Foroulis, F.S. Pettit Eds. (The Electrochemical Soc., 1976) p. 668.

[6] WELSCH G., KAHVECi A.I., Oxidation of High Temperature Intermetallics, T. Grobstein, J. Doychak Eds. (TMS PA, 1989) p. 207.

[7] Tortorelli P.F. et al., Intermetallic Matrix Composites, D.L. Anton et al. Eds., Vol. 194 (MRS PA, 1990) p. 361.

[8] NourbaKHSH S. et al., Metall. Trans. 21A (1990) 213.

[9] MisRa A.K., Metall. Trans. 22A (1991) 715.

[10] JANAF Thermochemical Tables, National Bureau of Standards (1971).

[11] WAGNER C., Z. Electrochem. 63 (1959) 772.

[12] NourbaKHSH S. et al., Metall. Trans. 22A (1991) 3059.

[13] Debuigne J., Met. Corros. Ind. 501 (1967) 186.

[14] Kofstad P., Diffusion and Electrical Conductivity in Binary Metal Oxides (WilerInterscience, 1972).

[15] Vykhodets V. et al., Phys. Met. Metall. 68 (1989) 145.

[16] PeRkins R.A. et al., Oxidation of High Temperature Intermetallics, T. Grobstein, J. Doychak Eds. (TMS PA, 1989) p. 157.

[17] KobaYASHi E. et al., High Temp. Technol. 8 (1990) 179. 